\title{
A tribute to Wartenberg's refined neurological examination
}

\author{
Um tributo ao refinado exame neurológico de Wartenberg \\ Péricles Maranhão-Filho', Renato Gonik²
}

\begin{abstract}
Robert Wartenberg was a renowned $20^{\text {th }}$ century neurologist who contributed greatly to our understanding of the neurological examination. This article aims to illustrate his legacy by highlighting five seminal neurological signs.
\end{abstract}

Keywords: Robert Wartenberg; neurologic examination.

\section{RESUMO}

Robert Wartenberg foi um renomado neurologista do século XX que contribuíu enormemente para o entendimento do exame neurológico. Este artigo tem como objetivo principal ilustrar seu legado, ressaltando cinco sinais neurológicos seminais.

Palavras-chave: Robert Wartenberg; exame neurológico.

Robert Wartenberg was born in 1887 in Grodno, Belarus, then part of the Russian Empire ${ }^{1}$. He received his medical degree from the University of Rostock, Germany, in 1919, and was, for many years, associated with the University of Freiburg, where he became Professor of Neurology in $1933^{2}$. With the Nazi regime in power, rising anti-Semitism led him to flee Germany in 1935. After relocating to the United States in 1936, he re-engaged in his neurology career at the University of California Medical School in San Francisco, where he was appointed Clinical Professor of Neurology in $1952^{2}$.

Wartenberg was an internationally recognized neurologist, earning an honorary membership in several foreign societies. Of note, in 1953, the California Medicine Journal ${ }^{3}$ published the following announcement: "Dr. Robert Wartenberg, clinical professor of neurology, University of California Hospital, has been elected a corresponding member of the Rio de Janeiro Society of Neurology".

Wartenberg's academic accomplishments were vast. He believed in a "sacred obligation" to his students, and reportedly his lectures were unforgettable events ${ }^{1}$. Wartenberg made over 150 scientific contributions, including four books': The Examination of Reflexes: A Simplification (1945)'; Hemifacial Spasm (1952)5; Diagnostic Tests in Neurology (1953)'; and Neuritis, Sensory Neuritis, Neuralgia (1958) 7 .

He was reputed to be one of the foremost semiologists of his time. He strived to abolish unnecessary eponym designations, leading an effort to replace them with designations that were descriptive of the underlying pathophysiology ${ }^{8}$. In fact, he was known to be very critical of the neurological literature, somewhat intolerant of carelessness, albeit with a constructive intent.

We pay homage to Wartenberg's tradition of simplifying the examination by briefly discussing five of his seminal neurological signs.

\section{TENDON PALPATION TEST}

A lesion of the lower motor neurons lead to muscle hypotonia, resulting in tendon slackness. This is best seen in the Achilles tendon. With the patient standing upright, weight equally distributed onto both legs, the examiner gently grasps the patient's ankles, placing his thumbs directly over the Achilles tendons. Pressure is gradually exerted over each tendon, while comparing the resistance offered against the thumbs (Figure 1).

In a normal person standing flat onto his feet, the Achilles tendon has a hard consistency. In unilateral lesions of the sciatic nerve the Achilles tendon has a softer consistency when compared to the normal side.

This sensitive test may indicate the presence of a lower motor neuropathy at a very early stage when no evidence of muscle wasting, weakness, or even diminished ankle jerk is present. A soft

\footnotetext{
1 Universidade Federal do Rio de Janeiro, Faculdade de Medicina, Serviço de Neurologia, Hospital Universitário Clementino Fraga Filho, Rio de Janeiro RJ, Brasil; ${ }^{2}$ Director, Clinical Neurophysiology Consultants, Hollywood, FL.

Correspondence: Péricles Maranhão-Filho; Rua Prefeito Dulcídio Cardoso, 1680/1802; 22260-311 Rio de Janeiro RJ, Brasil; E-mail: pmaranhaoflho@gmail.com Conflict of interest: There is no conflict of interest to declare.
}

Received 22 March 2016; Accepted 06 June 2016. 
Achilles tendon may thus be an early sign of sciatic neuropathy. When positive, this test corroborates an organic peripheral lesion of the nervous system, but a negative test cannot exclude it ${ }^{6}$.

\section{LID VIBRATION TEST}

The seemingly smooth process of sustained voluntary muscle contraction is a result of the continuous integration of multiple underlying discrete and successive contractions. This fine-tuning mechanism is evident in the orbicularis oculi as a palpable vibratory sensation that declines with weakness. It can be felt by applying gentle lateral traction at the outer canthus while the patient maintains forceful eyelid closure (Figure 2).

Diminished lid vibration is a very sensitive sign, occurring early in cases of slowly evolving facial palsy. Conversely, its return to normality occurs slowly and late in the process of recovery. In fact, it may remain diminished as a sole indication of an old facial palsy. As such, diminished lid vibration may be the first, as well as last, sign detected in the natural history of a facial palsy. Despite its sensitivity, it is not specific in distinguishing central from peripheral facial lesions, being present in both ${ }^{6}$.

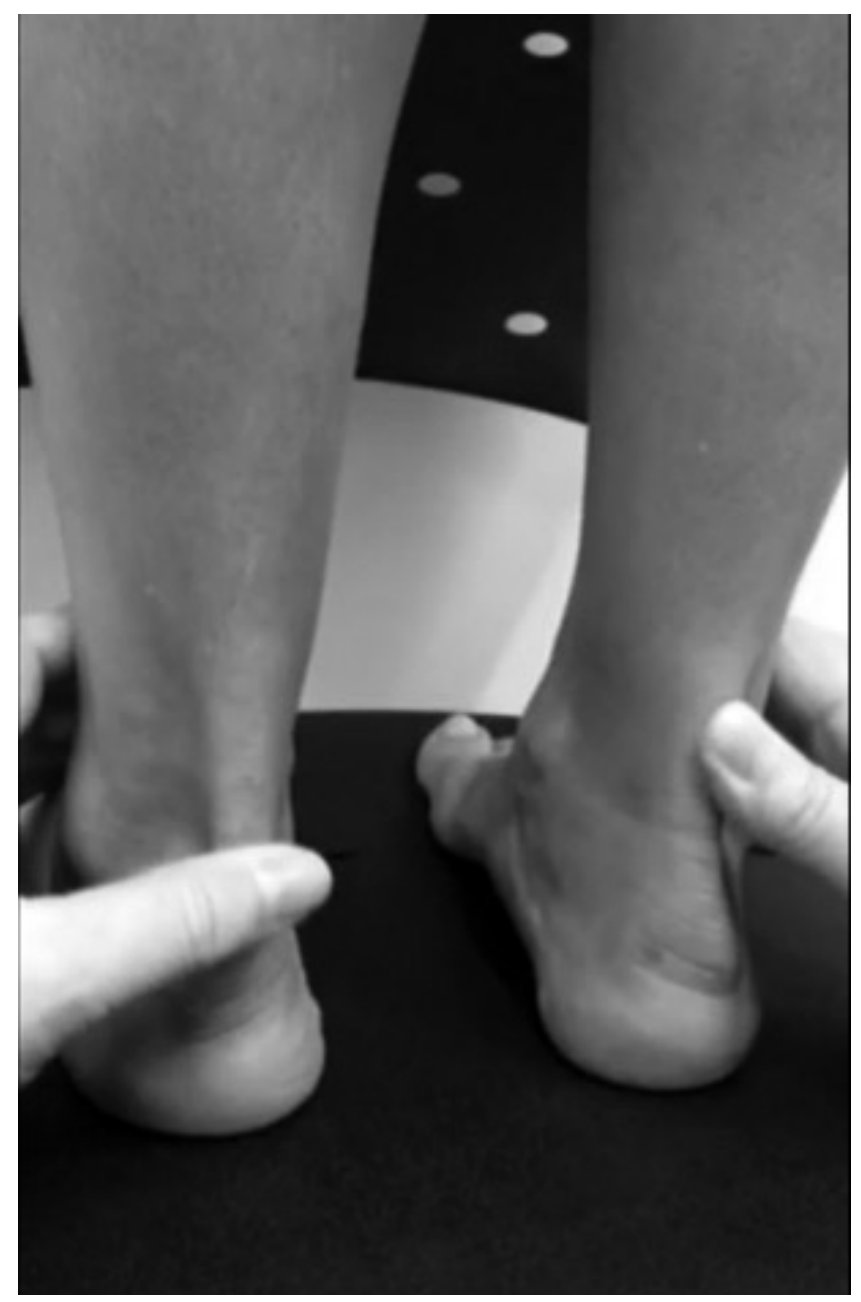

Figure 1. Tendon palpation test.

\section{ASSOCIATED MOVEMENT OF THE THUMB}

Volitional hand movements require precise control of agonist, antagonist, and synergist muscles. This orchestration is compromised by lesions of central descending motor pathways, resulting in unusual patterns of motor activation. One such pattern is observed in the spastic paretic hand as an associated movement of the thumb.

The patient is asked to pull his four fingers, flexed at the terminal phalanges, against resistance offered by the examiner's similarly flexed fingers (Figure 3).

In a normal person, the thumb remains extended and abducted. Conversely, spastic paresis of the hand results in involuntary thumb adduction, flexion, and opposition. This constitutes a very early sign, and may be seen in incipient spastic hand paresis 6 .

\section{WRIST DROPTEST}

Weakness of wrist extension results in a hand droop when the patient's pronated forearm is held horizontally, and fingers are relaxed. Inspection alone cannot differentiate if this phenomenon is due to a central or peripheral lesion. However, clenching the fingers while the hand is in this position can make this distinction $^{6}$ (Figure 4). Normally, flexion of the fingers is accompanied by extension at the wrist as an associated movement. This motor response is preserved with lesions affecting central motor pathways, and is lost with peripheral lesions.

The patient is asked to grasp an object with his affected hand. With peripheral lesions affecting the extensor musculature, such as a radial neuropathy, dorsiflexion is absent. In fact, wrist flexion may be accentuated by increasing effort to tighten the grip. With central lesions, wrist dorsiflexion occurs involuntarily.

\section{ACCESSORY NERVE TEST}

The spinal accessory nerve innervates the upper trapezius muscle, which acts to elevate the shoulder. This thin nerve lies superficially and is easily traumatized, often an iatrogenic lesion of the posterior triangle of the neck ${ }^{9}$.

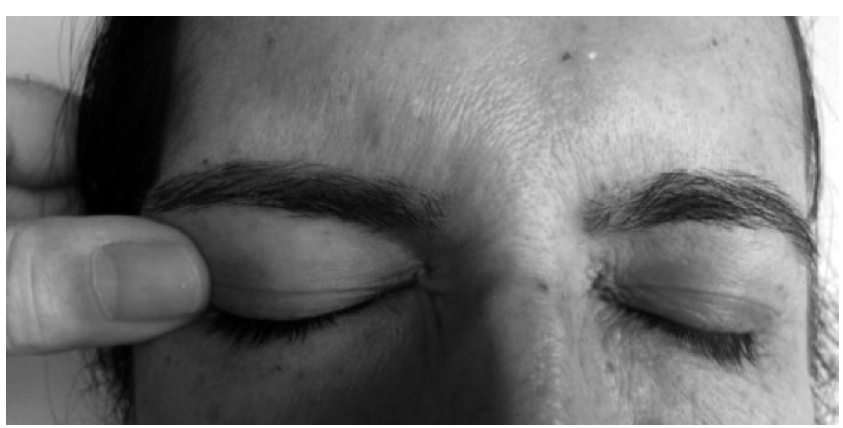

Figure 2. Method of lid vibration test. 


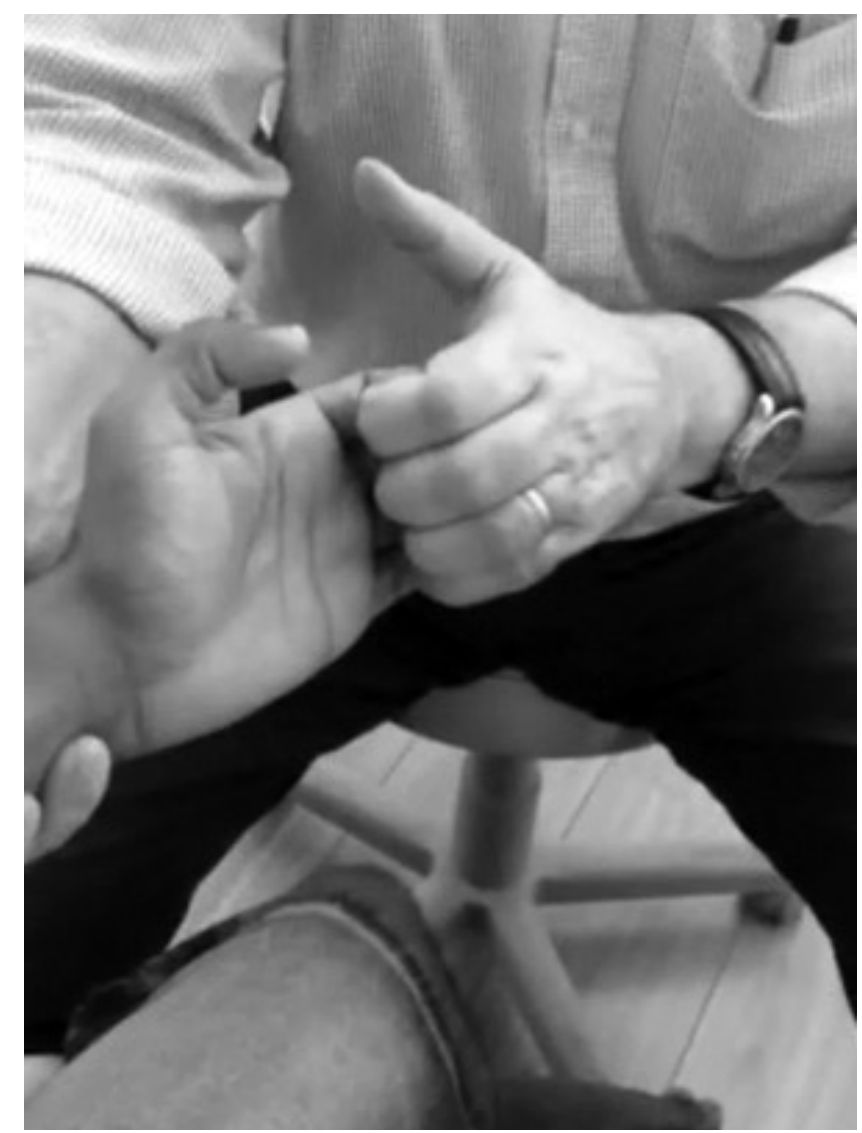

Figure 3. Associated movement of the thumb. In mild spastic paresis the thumb moves toward the palm. The examiner is wearing a wristwatch.
In the event of an accessory nerve lesion a shoulder droop occurs. This displacement results in an apparent length discrepancy of the upper limbs. The patient is examined upright with arms hanging loosely at the sides. The level at which the fingertips touch the thighs are compared. On the affected side the fingertips touch the thigh at a lower level than on the healthy side (Figure 5).

Robert Wartenberg was a respected figure in the global neurological community, in great measure due to his didactic acumen ${ }^{2}$. In today's overly technological environment, remembering Wartenberg's signs may rekindle the art of examination.

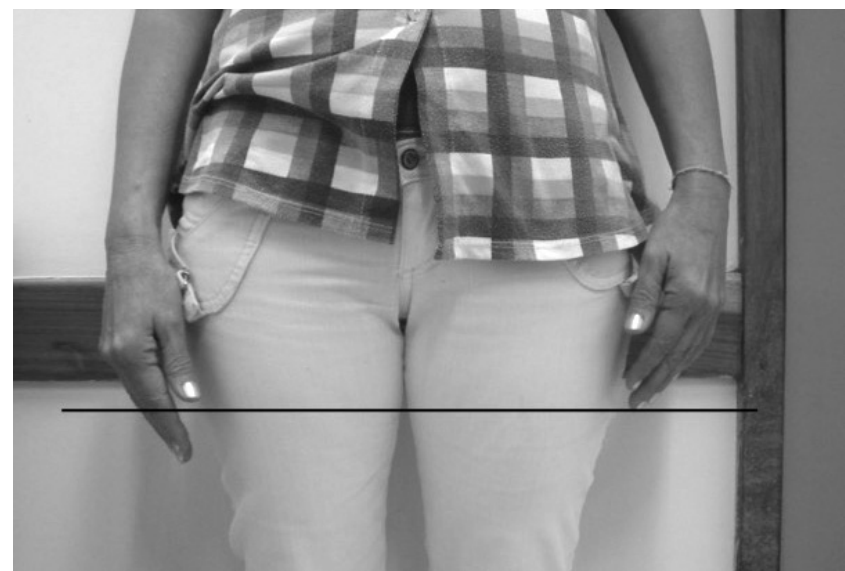

Figure 5. Accessory nerve test. Fingertips on affected side (right) extend below the level on healthy side (black line).
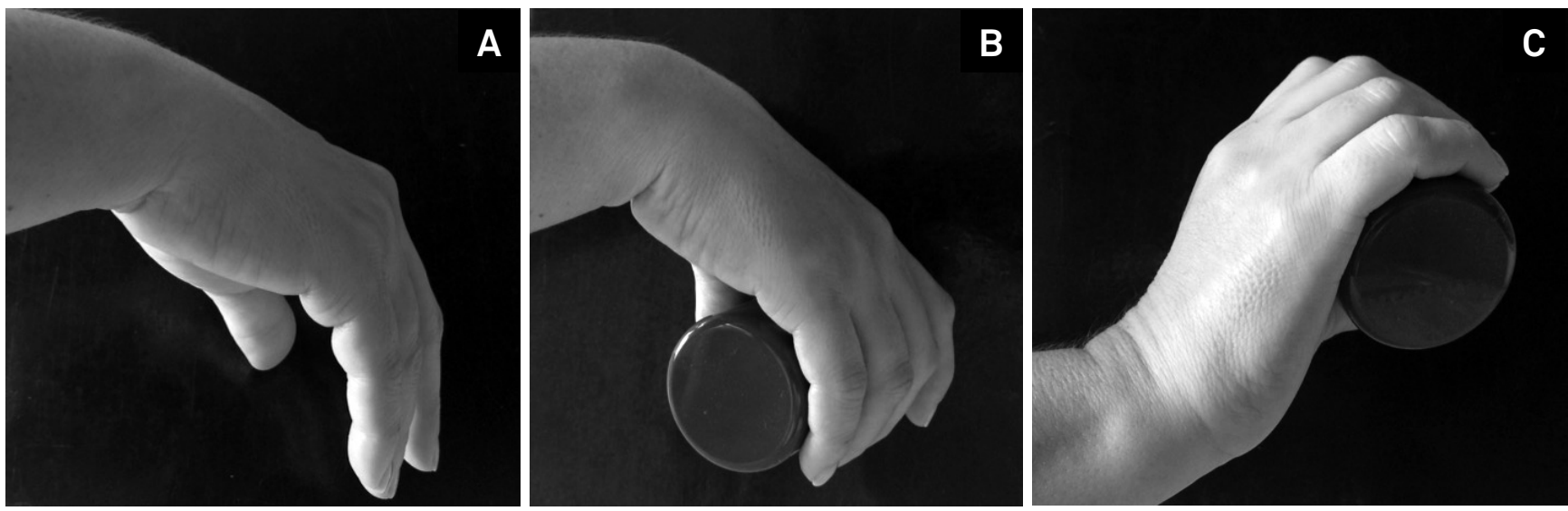

Figure 4. Wrist drop (A). In flaccid paresis wrist flexion is exacerbated (B). In spastic paresis involuntary wrist extension occurs (C).

\section{References}

1. Aird RB. Robert Wartenberg, MFF., 1887-1956. Neurology. 1957:7(2):146-47. doi:10.1212/WNL.7.2.146

2. Lange O. Homenagem póstuma: Prof. Robert Wartenberg. Arq Neuropsiquiatr. 1957;15(1):91-2. doi:10.1590/S0004-282X1957000100010

3. News \& Notes. California Medicine. 1953;78(4):332-3.

4. Wartenberg R. The examination of reflex a simplification. Chicago: The Year Book; 1945
5. Wartenberg R. Hemifacial spasm. New York: Oxford University Press; 1952.

6. Wartenberg R. Diagnostic test in neurology. Chicago:The Year Book; 1953.

7. Wartenberg R. Neuritis, sensory neuritis, neuralgia. New York: Oxford University Press; 1958.

8. Wartenberg R. On neurologic terminology, eponyms and the Lasègue sign. Neurology. 1956;6(12):853-8. doi:10.1212/WNL.6.12.853

9. Wills AJ., Sawle GV. Accessory nerve palsies. Pract Neurol. 2010;10:191-4. doi:10.1136/jnnp.2010.217760 